Revista Eletrônica de Direito Processual - REDP.

Rio de Janeiro. Ano 12. Volume 19. Número 1. Janeiro a Abril de 2018

Periódico Quadrimestral da Pós-Graduação Stricto Sensu em Direito Processual da UERJ

Patrono: José Carlos Barbosa Moreira (in mem.). ISSN 1982-7636. pp. 62-82

www.redp.uerj.br

\title{
PRECEDENTES OBRIGATÓRIOS, DESENVOLVIMENTO E SEGURANÇA JURÍDICA ${ }^{1}$
}

\section{MANDATORY PRECEDENTS, DEVELOPMENT AND LEGAL CERTAINTY}

\section{Claudia Maria Barbosa}

Pós-Doutora pela York University, Toronto, Canadá. Doutora e Mestre em Direito pela Universidade Federal de Santa Catarina, com pesquisa em sistemas jurídicos comparados realizada na Universidade de Montreal, CA. É professora titular da Pontifícia Universidade Católica do Paraná. Leciona nos cursos de graduação e nos programas de mestrado e doutorado em Direito da PUCPR. Advogada. Curitiba/PR. claudia.mr.barbosa@gmail.com

\section{Elson Pereira de Oliveira Bastos} Mestrando em Direito pela Pontifícia Universidade Católica do Paraná (PUCPR). Professor na Escola da Magistratura do Estado de Rondônia. Juiz de Direito em Rondônia. Jaru/RO. emeron.jpr.elson@gmail.com

RESUMO: A pesquisa pretende avaliar se os precedentes e súmulas obrigatórios consubstanciam uma proposta institucional para o desenvolvimento nacional e o respeito ao Direito, com a concretização dos valores e objetivos da nossa Constituição. Para tanto, procura-se demonstrar que a segurança jurídica é um valor de um sistema jurídico orientado ao desenvolvimento e também um princípio normativo que estabelece como fim a observância, na aplicação do Direito, de padrões jurídicos formalmente consistentes e substancialmente adequados, construídos intersubjetivamente. Fazendo uso do método dedutivo e da pesquisa bibliográfica, procura-se estudar a relação existente entre a vinculação aos precedentes e súmulas, de um lado, e o desenvolvimento e a valorização do Direito, de outro. Os resultados da pesquisa apontam que a reforma processual que

\footnotetext{
${ }^{1}$ Artigo recebido em 15/10/2017 e aprovado em 06/03/2018.
} 
Revista Eletrônica de Direito Processual - REDP.

Rio de Janeiro. Ano 12. Volume 19. Número 1. Janeiro a Abril de 2018

Periódico Quadrimestral da Pós-Graduação Stricto Sensu em Direito Processual da UERJ

Patrono: José Carlos Barbosa Moreira (in mem.). ISSN 1982-7636. pp. 62-82

www.redp.uerj.br

introduziu o sistema de precedentes obrigatórios no Brasil, sem bem operacionalizado, representa uma conquista importante para o aumento da segurança jurídica na aplicação do Direito e, por conseguinte, para a promoção do desenvolvimento e a realização das liberdades substantivas. Tudo isso é relevante para chamar a atenção da comunidade jurídica em relação ao cuidado e à crítica que deve ser constantemente endereçado ao sistema de precedentes brasileiro, a fim de que possa efetivamente cumprir a finalidade para o qual foi concebido, sintonizada com as premissas do nosso Estado Democrático de Direito.

PALAVRAS-CHAVE: Precedentes. Desenvolvimento. Segurança jurídica. Legitimidade. Poder Judiciário.

ABSTRACT: The research aims to evaluate whether the precedents and mandatory precedents constitute an institutional proposal for national development and respect for the law, with the realization of the values and objectives of our Constitution. In order to do so, it seeks to demonstrate that legal certainty is a value of a development-oriented legal system and also a normative principle that establishes as an aim the observance, in the application of the Law, of formally consistent and substantially adequate, intersubjectively constructed legal standards. Making use of the deductive method and the bibliographical research, it is tried to study the relation between the connection with precedents, on the one hand, and the development and valorization of Law, on the other. The results of the research point out that the procedural reform that introduced the system of mandatory precedents in Brazil, without well operationalized, represents an important achievement for the increase of legal certainty in the application of the Law and, therefore, for the promotion of the development and realization of substantive freedoms. All of this is relevant to draw the attention of the legal community regarding the care and criticism that must be constantly addressed the Brazilian previous system, so that it can effectively fulfill the purpose for which it was designed, tuned to the premises of our democratic state.

KEYWORDS: Precedent. Development. Legal certainty. Legitimacy. Judiciary. 
Revista Eletrônica de Direito Processual - REDP.

Rio de Janeiro. Ano 12. Volume 19. Número 1. Janeiro a Abril de 2018

Periódico Quadrimestral da Pós-Graduação Stricto Sensu em Direito Processual da UERJ

Patrono: José Carlos Barbosa Moreira (in mem.). ISSN 1982-7636. pp. 62-82

www.redp.uerj.br

\section{INTRODUÇÃO:}

O Código de Processo Civil prevê em seu art. 927 que os juízes e tribunais observarão as decisões do Supremo Tribunal Federal em controle concentrado de constitucionalidade; os enunciados de súmula vinculante; os acórdãos em incidente de assunção de competência ou resolução de demandas repetitivas e em julgamento de recursos extraordinário e especial repetitivos; os enunciados das súmulas do Supremo Tribunal Federal em matéria constitucional e do Superior Tribunal de Justiça em matéria infraconstitucional; além da orientação do plenário ou do órgão especial aos quais estiverem vinculados.

Com base nesse regramento, argumenta-se que foi instituído no Brasil um "sistema de precedentes". Seriam os chamados precedentes obrigatórios, os quais teriam força vinculante em relação aos juízes e tribunais incumbidos da sua aplicação.

A novidade é de crucial importância para a prática judiciária brasileira e influi diretamente no modo de desenvolvimento e aplicação da jurisprudência pelos juízes e tribunais. O objetivo mais modesto da reforma processual é conferir racionalidade ao modo como são operacionalizados os precedentes pelo Poder Judiciário. Uma análise mais profunda, porém, revela que os precedentes obrigatórios contribuem para a segurança jurídica e o processo de desenvolvimento nacional.

Desse modo, a pesquisa pretende avaliar se os precedentes e súmulas obrigatórios consubstanciam uma proposta institucional para o desenvolvimento nacional e o respeito ao Direito, com a concretização dos valores e objetivos da nossa Constituição. Nesse sentido, procura-se demonstrar que a segurança jurídica é um valor de um sistema jurídico orientado ao desenvolvimento e também um princípio normativo que estabelece como fim a observância, na aplicação do Direito, de padrões jurídicos formalmente consistentes e substancialmente adequados, construídos intersubjetivamente.

O trabalho foi desenvolvido com apoio no método de abordagem dedutivo, sendo a pesquisa do tipo qualitativa bibliográfica.

Analisa-se, em primeiro lugar, a relação entre a segurança jurídica e o desenvolvimento, com enfoque na teoria institucional, tomada a partir da obra de Douglass North, e no modelo ampliado do rule of law. Em um segundo momento, discorre-se sobre a segurança jurídica enquanto princípio normativo, portanto, como preceito de fundo 
Revista Eletrônica de Direito Processual - REDP.

Rio de Janeiro. Ano 12. Volume 19. Número 1. Janeiro a Abril de 2018

Periódico Quadrimestral da Pós-Graduação Stricto Sensu em Direito Processual da UERJ

Patrono: José Carlos Barbosa Moreira (in mem.). ISSN 1982-7636. pp. 62-82

www.redp.uerj.br

deontológico, que prescreve um estado de coisas a ser buscado. Por fim, examina-se a relação entre os precedentes obrigatórios e a segurança jurídica, passando pelo problema da jurisprudência lotérica, discutindo-se, em seguida, o mecanismo da vinculação aos precedentes como via de fortalecimento do Poder Judiciário em meio ao desenvolvimento e, finalmente, o papel que desempenha a segurança jurídica para um sistema normativo fundado no e pelo Direito.

Também são delineados aportes críticos ao sistema de precedentes genuinamente brasileiro, uma vez que pode ser desvirtuado e convolar-se em mecanismo de "elitização" e de pura racionalidade econômica do Direito, o que conspiraria contra a Constituição e as conquistas históricas do que se compreende por Estado Democrático de Direito.

\section{DESENVOLVIMENTO E SEGURANÇA JURÍDICA}

A segurança jurídica é uma condição inexorável do processo de desenvolvimento. Sem o estabelecimento das regras que orientam as atividades dos agentes econômicos, não é possível criar um ambiente propício ao investimento e à geração de emprego e renda. Como assinala Eros Roberto Grau, "[S]em a calculabilidade e a previsibilidade instaladas pelo direito moderno o mercado não poderia existir"2.

É importante desde logo esclarecer que o desenvolvimento distingue-se do mero crescimento econômico. O crescimento econômico está associado a um processo de elevação da renda per capita. Nesse sentido, significa "um processo contínuo pelo qual a disponibilidade de bens e serviços cresce em proporção superior ao do incremento demográfico de uma dada sociedade" ${ }^{3}$. Essa é uma noção apenas parcial ou incompleta do que se entende por desenvolvimento, uma vez que despreza os elementos concernentes à qualidade de vida e promoção das capacidades das pessoas.

O termo desenvolvimento, portanto, tem significado mais amplo do que o simples crescimento econômico e "envolve uma série infindável de modificações de ordem

\footnotetext{
${ }^{2}$ GRAU, Eros Roberto. A Ordem Econômica na Constituição de 1988. $14^{\mathrm{a}}$ ed. São Paulo: Malheiros, 2010 , p. 30.

${ }^{3}$ NUSDEO, Fábio. Curso de Economia: introdução ao Direito Econômico. $8^{\text {a }}$ ed. São Paulo:Revista dos Tribunais, 2014, p. 371.
} 
Revista Eletrônica de Direito Processual - REDP.

Rio de Janeiro. Ano 12. Volume 19. Número 1. Janeiro a Abril de 2018

Periódico Quadrimestral da Pós-Graduação Stricto Sensu em Direito Processual da UERJ

Patrono: José Carlos Barbosa Moreira (in mem.). ISSN 1982-7636. pp. 62-82

www.redp.uerj.br

qualitativa e quantitativa, de tal maneira a conduzir a uma radical mudança de estrutura da economia e da própria sociedade" ${ }^{4}$.

Um conceito de desenvolvimento radicalmente vinculado à promoção da dignidade das pessoas é encontrado em Amartya Sen, nobel de economia. Para Amartya Sen, a expansão de liberdades substantivas ${ }^{5}$ é o que caracteriza o desenvolvimento. Isso implica "que se removam as principais fontes de privação de liberdade: pobreza e tirania, carência de oportunidades econômicas e destituição social sistemática, negligência dos serviços públicos e intolerância ou interferência excessiva de Estados repressivos" "6.

Duas são as razões pelas quais Amartya Sen reconhece a centralidade da liberdade para o processo de desenvolvimento. A primeira é a "razão avaliatória", baseada na premissa de que o progresso só tem sentido se aumentar as liberdades das pessoas. A segunda é a "razão da eficácia", fundada na ideia de que o desenvolvimento é condicionado pela livre condição de agente das pessoas ${ }^{7}$.

Uma explicação mais simples para a relação entre a liberdade e o desenvolvimento é a de que "o que as pessoas conseguem positivamente realizar é influenciado por oportunidades econômicas, liberdades políticas, poderes sociais e por condições habilitadoras como boa saúde, educação básica e incentivo e aperfeiçoamento de iniciativas" $"$.

Essa é uma noção que está diretamente ligada à concepção de Estado Social, cuja representação atribui "ao estado e à ordem jurídica o papel de realizar a justiça social, de propiciar ou fornecer a cada um as condições necessárias de uma vida digna e de um pleno desenvolvimento da sua personalidade e lhes impõe o dever de o realizar"”.

\footnotetext{
${ }^{4}$ Ibid. p. 372.

5 "As liberdades substantivas incluem capacidades elementares como por exemplo ter condições de evitar privações como a fome, a subnutrição, a morbidez evitável e a morte prematura, bem como liberdades associadas a saber ler e fazer cálculos aritméticos, ter participação política e liberdade de expressão etc. Nessa perspectiva constitutiva, o desenvolvimento envolve a expansão dessas e de outras liberdades básicas: é o processo de expansão das liberdades humanas...” (SEN, Amartya. Desenvolvimento como liberdade. Tradução de Laura Teixeira Motta. São Paulo: Companhia das Letras, 2010, p. 55).

6 SEN, Amartya. Desenvolvimento como liberdade. Tradução de Laura Teixeira Motta. São Paulo: Companhia das Letras, 2010, p. 16-17.

${ }^{7}$ Ibid. p. 17.

${ }^{8}$ Ibid. p. 18.

${ }^{9}$ MOREIRA, Vital. A ordem jurídica do capitalismo. 3. ed., Coimbra: Centelho, 1978, p. 119.
} 
Revista Eletrônica de Direito Processual - REDP.

Rio de Janeiro. Ano 12. Volume 19. Número 1. Janeiro a Abril de 2018

Periódico Quadrimestral da Pós-Graduação Stricto Sensu em Direito Processual da UERJ

Patrono: José Carlos Barbosa Moreira (in mem.). ISSN 1982-7636. pp. 62-82

www.redp.uerj.br

\subsection{Instituições jurídicas}

Os arranjos institucionais consubstanciam um ferramental importantíssimo para a promoção da segurança jurídica. Bruno Meyerhof Salam assinala que "[A] incerteza é onipresente e boa parte das atividades humanas ao longo da história pode ser interpretada como constituindo tentativas de redução da incerteza" ${ }^{10}$. As instituições servem a esse fim, estabelecendo ordem e reduzindo a incerteza ${ }^{11}$.

Douglas North diz que as instituições são as "regras do jogo em uma sociedade"12. Há dois tipos de instituições, formais e informais, sendo que ambas restringem a atuação dos indivíduos e entes sociais. A partir delas, as pessoas em geral e os agentes econômicos, em particular, enxergam o ambiente em que suas ações serão realizadas, podendo antever, em maior ou menor medida, as respectivas consequências e resultados.

As instituições de natureza jurídica compreendem um dos principais ingredientes definidores das mencionadas "regras do jogo". Sendo assim, é sem dúvida que o direito tem elevando potencial para afetar o crescimento econômico ${ }^{13}$. A influência das instituições jurídicas no esquema do desenvolvimento nacional, contudo, segundo North, vai depender da solução que é dada à problemática entre a estrutura jurídica de um lado e o crescimento econômico, de outro, a qual revela a tensão entre a necessidade de estabilidade jurídica, com implicações para a ordem e controle da violência, e a necessidade de abertura

\footnotetext{
${ }^{10}$ SALAM, Bruno Meyerhof. Sete enigmas do desenvolvimento em Douglass North. In: VIEIRA, Oscar Vilhena; DIMOULIS, Dimitri (Org.). Estado de Direito e o Desafio do Desenvolvimento. São Paulo: Sariva, 2011, p. 45.

11 "Institutions reduce uncertainty by providing a structure to everyday life" (NORTH, Douglass Cecil. Institutions, institutional change and economic performance. New York: Cambridge, 1990, p. 3).

${ }^{12}$ NORTH, Douglass Cecil. Institutions, institutional change and economic performance. New York: Cambridge, 1990, p. 3.

${ }^{13}$ Bruno Meyerhof Salam adverte que: "Surgem, então, dois problemas para se pensar os mecanismos através dos quais o direito afeta o arcabouço institucional. Em primeiro lugar, as instituições informais (como normas sociais de comportamento, códigos de conduta, convenções, valores, crenças, tabus, costumes, religiões etc.) não são plenamente controláveis. E, em segundo lugar, o Estado tem limitações na sua capacidade de fazer cumprir ("enforce") as leis e regulamentos formais. Esse quadro, portanto, sugere um limite bastante claro ao papel do direito nos projetos de mudança social: as instituições importam e o direito não é mera superestrutura, mas isso não quer dizer que o direito tudo possa" (SALAM, Bruno Meyerhof. Sete enigmas do desenvolvimento em Douglass North. In: VIEIRA, Oscar Vilhena; DIMOULIS, Dimitri (Org.). Estado de Direito e o Desafio do Desenvolvimento. São Paulo: Sariva, 2011, p. 52-53).
} 
Revista Eletrônica de Direito Processual - REDP.

Rio de Janeiro. Ano 12. Volume 19. Número 1. Janeiro a Abril de 2018

Periódico Quadrimestral da Pós-Graduação Stricto Sensu em Direito Processual da UERJ

Patrono: José Carlos Barbosa Moreira (in mem.). ISSN 1982-7636. pp. 62-82 www.redp.uerj.br

à mudança, esta com reflexos à abertura da ordem social para o processo de desenvolvimento ${ }^{14}$.

\subsection{O Rule of Law}

O rule of law, sob a perspectiva econômica, identifica um arranjo institucional capaz de contribuir para o desenvolvimento dos Estados Nacionais ${ }^{15}$. Na base de sua idealização está a premissa de que o desenvolvimento pressupõe "regras do jogo claras e estáveis, capazes de promover um ambiente econômico seguro para o mercado..." $"$.

Embora o rule of law seja geralmente concebido sob uma perspective liberal, com ênfase ao papel secundário do Estado no plano econômico, há um forte debate doutrinário a esse respeito, inexistindo uma posição única sobre a sua formatação. Salem Hikmat Nasser, referindo-se a Joseph Raz, fala de um sentido mais abrangente do rule of law, como obediência e governo pelo direito ${ }^{17}$.

O sistema jurídico, portanto, não é algo que possa ser negligenciado em um Estado que aspire ao desenvolvimento. Embora as especificidades de cada sociedade, resultantes do processo histórico, não permitam a identificação de um modelo único, há sem dúvida alguns traços gerais que influenciam o modelo do rule of law. Essas características gerais dizem respeito tanto às normas e à sua produção quanto às instituições encarregadas de aplicá-las $^{18}$.

Do lado das normas e sua elaboração, podem ser mencionadas as seguintes características: necessidade de que as normas sejam prospectivas, claras e abertas; normas estáveis; modo de produção das normas segundo padrões gerais, estáveis e claros. No

\footnotetext{
${ }^{14}$ SALAM, Bruno Meyerhof. Sete enigmas do desenvolvimento em Douglass North. In: VIEIRA, Oscar Vilhena; DIMOULIS, Dimitri (Org.). Estado de Direito e o Desafio do Desenvolvimento. São Paulo: Sariva, 2011, p. 52.

${ }^{15}$ RIBEIRO, Marcia Carla Pereira; ALVES, G. R. R. Desenvolvimento e Reforma Institucional: os exemplos do BNDES e das Sociedades Estatais no Brasil. In: SILVEIRA, Vladimir Oliveira da; SANCHES, Samyra Naspolini; COUTO, Monica Bonetti (Org.). Direito e Desenvolvimento no Brasil do Século XXI. IPEA: Brasília, 2013, v. 1, p. 153.

${ }^{16}$ RIBEIRO, Marcia Carla Pereira; ALVES, G. R. R. Desenvolvimento e Reforma Institucional: os exemplos do BNDES e das Sociedades Estatais no Brasil. In: SILVEIRA, Vladimir Oliveira da; SANCHES, Samyra Naspolini; COUTO, Monica Bonetti (Org.). Direito e Desenvolvimento no Brasil do Século XXI. IPEA: Brasília, 2013, v. 1, p. 153.

${ }^{17}$ NASSER, Salem Hikmat. Rule of Law e Direito Internacional: uma nova aproximação. In: VIEIRA, Oscar Vilhena; DIMOULIS, Dimitri (Org.). Estado de Direito e o Desafio do Desenvolvimento. São Paulo: Sariva, 2011, p. 64.

${ }^{18}$ Ibid. p. 64.
} 
Revista Eletrônica de Direito Processual - REDP.

Rio de Janeiro. Ano 12. Volume 19. Número 1. Janeiro a Abril de 2018

Periódico Quadrimestral da Pós-Graduação Stricto Sensu em Direito Processual da UERJ

Patrono: José Carlos Barbosa Moreira (in mem.). ISSN 1982-7636. pp. 62-82

www.redp.uerj.br

grupo alusivo às instituições responsáveis pela aplicação são listadas as seguintes

características: independência do Judiciário; observância de certos princípios, tal como a imparcialidade; poder de revisão dos tribunais e; facilidade de acesso aos tribunais (acesso à justiça) ${ }^{19}$.

As regras legais funcionam como incentivos ou inibidores de condutas ${ }^{20}$. Uma legislação que não afeta as decisões já tomadas, que seja compreensível e estável ao mesmo tempo em que permita adaptação ao processo de evolução social apresenta-se como um sinalizador que orienta as ações das pessoas e entes em geral, gerando previsibilidade e calculabilidade. O cenário oposto revelaria um ordenamento jurídico precário com reflexos negativos para o sistema de preços, com aumento dos custos de transação e redução da eficiência alocativa da economia ${ }^{21}$.

\section{SEGURANÇA JURÍDICA COMO PRINCÍPIO NORMATIVO}

A segurança jurídica é uma característica essencial do direito, um valor fundamental para qualquer sistema jurídico ${ }^{22}$. Mesmo que o bem comum exija certo grau de flexibilidade do Direito, tendo em vista a mudança que sofrem os valores sociais, a necessidade de segurança jurídica continua sempre presente, pois as pessoas precisam ter consciência das consequências jurídicas de seus comportamentos ${ }^{23}$.

Vista como um princípio jurídico, a segurança jurídica impele para um estado de coisas que deve ser buscado ${ }^{24}$. Humberto Ávila ${ }^{25}$ explica que, nessa concepção, segurança

\footnotetext{
${ }^{19}$ Ibid. p. 64.

${ }^{20}$ ROCHA, Lara Bonemer Azevedo da. O desenvolvimento Econômico pelo Acesso à Justiça. Birigui, SP: Boreal Editora, 2015, p. 23.

${ }^{21}$ ROCHA, Lara Bonemer Azevedo da. O desenvolvimento Econômico pelo Acesso à Justiça. Birigui, SP: Boreal Editora, 2015, p, 24.

${ }^{22}$ MACÊDO, Lucas Buril. Precedentes Judiciais e o Direito Processual Civil. Salvador: Juspodivum, 2015, p. 118.

23 "O binômio segurança-estabilidade, tenazmente perseguido pelo Direito, estáo, como antes dito, em constante tensão com a mutação-instabilidade próprias da vida e dos acontecimentos sociais, afirmando Gustavo Terra Elias, reportando-se a Heráclito, que o Direito 'quer estabilizar a realidade, mas a realidade tem o ímpeto da evolução permanente" (MANCUSO, Rodolfo de Camargo. Sistema Brasileiro de Precedentes. $2^{\text {a }}$ ed. São Paulo: Revista dos Tribunais, 2016, p. 174.).

${ }^{24}$ ÁVILA, Humberto. Teoria da Segurança Jurídica. 4a ed. São Paulo: Malheiros, 2016, p. 127.

${ }^{25} \mathrm{O}$ autor trabalha com as seguintes categorias da segurança jurídica: como fato, como valor e como norma. E explica: "uma coisa é o fato de os julgadores aplicarem o ordenamento jurídico a fim de confirmar as previsões feitas para a maioria das suas decisões; outra é a asserção de que é muito melhor um ordenamento previsível que um imprevisível; e outra, ainda, a obrigação de os julgadores aplicarem o ordenamento de
} 
Revista Eletrônica de Direito Processual - REDP.

Rio de Janeiro. Ano 12. Volume 19. Número 1. Janeiro a Abril de 2018

Periódico Quadrimestral da Pós-Graduação Stricto Sensu em Direito Processual da UERJ

Patrono: José Carlos Barbosa Moreira (in mem.). ISSN 1982-7636. pp. 62-82

www.redp.uerj.br

jurídica não quer dizer previsão de consequências jurídicas de fatos ou de comportamentos,

"mas sim a prescrição para alguém adotar comportamentos que aumentem o grau de previsibilidade" 26 .

Como princípio normativo, a segurança jurídica "é uma concepção juspositivista argumentativa" ${ }^{27}$. Isso porque ao mesmo tempo em que decorre do Direito posto (direito positivo), sua realização é dependente da "reconstrução de sentidos normativos por meio de estruturas argumentativas e hermenêuticas" $" 28$.

Sendo um princípio jurídico, a segurança jurídica visa a um estado de coisas a ser promovido (aspecto finalístico). Seu conteúdo material, nesse sentido (quanto ao fim), é tanto a cognoscibilidade ou compreensibilidade, quanto a confiabilidade e a calculabilidade.

A cognoscibilidade refere-se à "elevada capacidade do cidadão de compreender os sentidos possíveis de um texto normativo, a partir de núcleos de significação a serem reconstruídos por meio de processos argumentativos intersubjetivamente controláveis" ${ }^{29}$. A confiabilidade relaciona-se à "proteção de situações subjetivas já garantidas individualmente e a exigência de continuidade do ordenamento jurídico por meio de regras de transição e de cláusulas de equidade" 30 . Por fim, a calculabilidade diz com a "elevada capacidade de prever as consequências jurídicas de atos ou fatos pela maioria das pessoas" ${ }^{31}$, ou seja, antecipar, em elevado grau, possibilidades interpretativas e consequências práticas das normas jurídicas.

Ao lado do conteúdo material da segurança jurídica, Humberto Ávila também elucida o seu aspecto objetivo, que concerne ao próprio objeto do princípio normativo em análise, podendo ser encarado como "segurança normativa" (segurança do ordenamento jurídico ou de uma norma específica) ou "segurança da aplicação do direito" (sua aplicação uniforme e não-arbitrária) $)^{32}$.

modo a aumentar a probabilidade de previsões das suas decisões por parte dos operadores do Direito" (ÁVILA, Humberto. Teoria da Segurança Jurídica. $4^{\text {a }}$ ed. São Paulo: Malheiros, 2016, p. 128).

${ }^{26}$ ÁVILA, Humberto. Teoria da Segurança Jurídica. $4^{\mathrm{a}}$ ed. São Paulo: Malheiros, 2016, p. 128.

${ }^{27}$ Ibid. p. 128.

${ }^{28}$ Ibid. p. 128.

${ }^{29}$ ÁVILA, Humberto. Teoria da Segurança Jurídica. $4^{\mathrm{a}}$ ed. São Paulo: Malheiros, 2016, p. 141.

${ }^{30}$ Ibid. p. 142.

${ }^{31}$ Ibid. p. 144 .

${ }^{32}$ Ibid. p. 156-160. 
Revista Eletrônica de Direito Processual - REDP.

Rio de Janeiro. Ano 12. Volume 19. Número 1. Janeiro a Abril de 2018

Periódico Quadrimestral da Pós-Graduação Stricto Sensu em Direito Processual da UERJ

Patrono: José Carlos Barbosa Moreira (in mem.). ISSN 1982-7636. pp. 62-82

www.redp.uerj.br

No que diz respeito ao este último aspecto (segurança da aplicação do direito), os elementos argumentativos e processuais são os determinantes de sua realização. Elementos argumentativos são "estruturas claras e objetivas de raciocínio, presentes quando as premissas e as conclusões do raciocínio jurídico são esclarecidas e fundadas no ordenamento jurídico"33. Nesse caso, a argumentação segue critérios racionais, apresentando consistência formal e coerência material. Os elementos processuais cuidam da observância de um procedimento caracterizado pela ampla defesa e o contraditório, administrativo ou judicial ${ }^{34}$.

Dessa maneira, a segurança jurídica, como princípio normativo, exerce várias funções eficaciais e argumentativas, sendo por isso mesmo um imperativo tanto para a produção quanto para a aplicação do Direito. Trata-se, portanto, de uma garantia aos direitos fundamentais e de moderação da atuação estatal ${ }^{35}$.

\section{OS PRECEDENTES OBRIGATÓRIOS E A SEGURANÇA JURÍDICA}

Nos dias atuais é inegável a influência que os julgamentos dos tribunais mais elevados exercem sobre a comunidade jurídica e na configuração e conformação de um direito ou obrigação ${ }^{36}$. Esse crescente aumento da importância das manifestações jurisdicionais é um fenômeno mundial que se intensificou após a Segunda Grande Guerra.

Diante disso, os precedentes ganham força mesmo nos países de tradição civil law. Três razões gerais são apontadas como justificativas ${ }^{37}$. A primeira refere-se ao reconhecimento de que o instante da aplicação da norma ao caso concreto é o mais relevante da fenomenologia jurídica. A segunda liga-se a gradativa superação do modelo de Estado Legislativo, de feição liberal, cuja preocupação precípua girava em torno dos direitos de liberdade, pelo modelo de Estado Constitucional, que atende a demandas próprias de um Estado Social e cuja preocupação gravita em torno da realização dos valores constitucionais e concretização das promessas da modernidade. A terceira razão é de ordem prática e diz respeito à facilidade de acesso às decisões dos tribunais superiores.

\footnotetext{
${ }^{33}$ Ibid. p. 160.

${ }^{34}$ Ibid. p. 160.

${ }^{35}$ Conf. ÁVILA, p. 682.

36 LOPES FILHO, Juraci Mourão. Os Precedentes Judiciais no Constitucionalismo Brasileiro Contemporâneo. $2^{\text {a }}$ ed. Salvador: Juspodivm, 2016, p. 23.

${ }^{37}$ Conf. LOPES FILHO, p. 29-30.
} 
Revista Eletrônica de Direito Processual - REDP.

Rio de Janeiro. Ano 12. Volume 19. Número 1. Janeiro a Abril de 2018

Periódico Quadrimestral da Pós-Graduação Stricto Sensu em Direito Processual da UERJ

Patrono: José Carlos Barbosa Moreira (in mem.). ISSN 1982-7636. pp. 62-82

www.redp.uerj.br

Corolário desse aumento de importância, a doutrina de um modo geral e as

instituições internas de um modo particular passaram a dedicar tempo e esforços a essa nova realidade, premidos pela busca de racionalidade e a necessidade de organização, já que os precedentes, assim como qualquer outro parâmetro normativo, requerem ordenação e sistematização.

Os assim denominados precedentes obrigatórios emergiram no cenário processual brasileiro como instrumentos aptos a constranger a atuação dos juízes e tribunais. Com base no aporte teórico da Nova Escola Institucional, trata-se de arranjo institucional formal que limita a atuação dos agentes públicos incumbidos da aplicação do Direito. Esse novel instrumental introduzido no ordenamento jurídico brasileiro pelo novo Código de Processo Civil tem como objetivo último a elevação da segurança jurídica no campo da aplicação do Direito $^{38}$.

É importante divisar que o chamado sistema de precedentes no Brasil tem características próprias, não se confundindo com o precedente do common law ${ }^{39}$. Aqui o precedente emerge da interpretação dos textos legais, a partir da identificação da norma geral do caso concreto (ratio decidendi), elemento nuclear do precedente. Quando reiteradamente aplicado, o precedente se transforma em jurisprudência, podendo ainda dar ensejo à edição de um enunciado na súmula da jurisprudência do tribunal. Em outras palavras, "a súmula é o enunciado normativo (texto) da ratio decidendi (norma geral) de uma jurisprudência dominante, que é a reiteração de um precedente". ${ }^{40}$

\footnotetext{
38 "Três valores principais justificam a adoção de um sistema de precedentes normativos ou vinculantes: a segurança jurídica, a isonomia e a eficiência” (MELLO, Patrícia Perrone Campos; BARROSO, Luis Roberto. Trabalhando com uma nova lógica: a ascensão dos precedentes no direito brasileiro. Revista Eletrônica Consultor Jurídico, 2016, p. 17. Disponível em: < http://s.conjur.com.br/dl/artigo-trabalhando-logicaascensao.pdf>. Acesso em: 29 jul. 2017).

39 “(...) após uma breve análise do common law, e, respectivamente, da doutrina dos precedentes e do sistema do stares decisis, torna-se fácil constatar a impossibilidade de pretender instituir esses mecanismos no Brasil, mediante alterações legislativas" (ABBOUD, Georges. Processo Constitucional Brasileiro. São Paulo: Revista dos Tribunais, 2016, p. 558).

${ }^{40}$ DIDIER JR., Fredie; BRAGA, Paula Sarno; OLIVIERA, Rafael Alexandria de. Curso de Direito Processual Civil: teoria da prova, direito probatório, decisão, precedente, coisa julgada e tutela provisória. Salvador: Juspodivum, 2015, v. 2, p. 487.
} 
Revista Eletrônica de Direito Processual - REDP.

Rio de Janeiro. Ano 12. Volume 19. Número 1. Janeiro a Abril de 2018

Periódico Quadrimestral da Pós-Graduação Stricto Sensu em Direito Processual da UERJ

Patrono: José Carlos Barbosa Moreira (in mem.). ISSN 1982-7636. pp. 62-82

www.redp.uerj.br

\subsection{A jurisprudência lotérica e a fragilização do sistema de justiça}

O fenômeno da imprevisibilidade da decisão judicial faz parte do imaginário dos operadores do direito brasileiro. Muito já se escreveu sobre isso ${ }^{41}$ e a prática diária bem o revela. Na base do problema está a subjetividade ${ }^{42}$, fomentadora de decisões pautadas na exclusiva "consciência do julgador" 43 . Sabe-se que a interpretação conduz a uma excepcional criação judicial do direito no sistema civil law. Não por outra razão que "os limites do ato interpretativo constituem uma das principais questões de política judiciária no mundo romano-germânico". 44

Vários fatores contribuem para esse estado de coisas. O primeiro e mais candente deles é inequivocamente o aprisionamento a um paradigma filosófico ${ }^{45}$ superado desde o denominado giro-linguístico, marcado pela obra de Ludwing Wittgenstein, quando a filosofia da consciência deu lugar à filosofia da linguagem ${ }^{46}$. Nas palavras de Lenio Streck:

Com o giro ontológico-linguístico, o sujeito não é fundamento do conhecimento (...) [I] sto quer dizer que o sentido não estará mais na consciência (de si do pensamento pensante), mas, sim, na linguagem pública, como algo que produzimos e que é condição de nossa possibilidade de estarmos no mundo. ${ }^{47}$

Além da questão filosófica, outros fatores podem ser citados a título de exemplos, como as ideias acríticas em relação à independência funcional dos juízes, ao princípio do juiz natural e à garantia de acesso à justiça ${ }^{48}$.

\footnotetext{
${ }^{41}$ ROCHA, Lara Bonemer Azevedo da. O desenvolvimento Econômico pelo Acesso à Justiça. Birigui, SP: Boreal Editora, 2015, p. 69s; GOUVEIA, Lúcio Grassi; BREITENBACH, Fábio Gabriel. Sistema de precedentes no novo Código de Processo Civil brasileiro: um passo para o enfraquecimento da jurisprudência lotérica dos tribunais. In: DIDIER JR, Fredie ... [et al.] (Coord.). Precedentes. Salvador: Juspodivm, 2015.

${ }^{42}$ STRECK, Lenio Luiz. O que é isto - decido conforme a minha consciência? $3^{\mathrm{a}}$ ed. Porto Alegre:

Livraria do Advogado, 2012.

${ }^{43}$ Propondo um sistema de precedentes sob a perspectiva do controle do ativismo judicial: ROCHA, Lara Bonemer Azevedo da; BARBOSA, Claudia Maria. O papel dos precedentes para o controle do ativismo judicial no contexto pós-positivista. Revista Brasileira de Políticas Públicas, v. 5, 2015.

${ }_{44}$ BARBOSA, Claudia Maria. O Processo de Legitimação do Poder Judiciário. Manaus: CONPEDI. Disponível em: < http://www.publicadireito.com.br/conpedi/manaus/arquivos/anais/XIVCongresso/080.pdf>. Acesso em: 12 out. 2017, p. 12.

${ }^{45}$ STRECK, Lenio Luiz. Verdade e Consenso. $4^{\mathrm{a}}$ ed. São Paulo: Saraiva, 2011, p. 217.

${ }^{46}$ GOUVEIA, Lúcio Grassi; BREITENBACH, Fábio Gabriel. Sistema de precedentes no novo Código de Processo Civil brasileiro: um passo para o enfraquecimento da jurisprudência lotérica dos tribunais. In: DIDIER JR, Fredie ... [et al.] (Coord.). Precedentes. Salvador: Juspodivm, 2015, p. 495-496.

${ }^{47}$ STRECK, Lenio Luiz. Dicionário de Hermenêutica. Belo Horizonte: Letramento: Casa do Direito, 2017, p. 87.

${ }^{48}$ Conf., MARINONI, Luiz Guilherme. Precedentes Obrigatórios. $4^{\mathrm{a}}$ ed. São Paulo: Revista dos Tribunais, 2016, p. 139-153.
} 
Revista Eletrônica de Direito Processual - REDP.

Rio de Janeiro. Ano 12. Volume 19. Número 1. Janeiro a Abril de 2018

Periódico Quadrimestral da Pós-Graduação Stricto Sensu em Direito Processual da UERJ

Patrono: José Carlos Barbosa Moreira (in mem.). ISSN 1982-7636. pp. 62-82

www.redp.uerj.br

Explorar cada um desses fatores foge ao propósito deste trabalho. Pretende-se, contudo, expor os malefícios que o seu conjunto acarreta ao sistema de justiça e, por conseguinte, à segurança jurídica.

Em primeiro lugar, a loteria judicial aumenta o tempo de duração do processo, pois cria a expectativa, para o derrotado, de que uma nova decisão favorável é em tese sempre possível. Como parte do mesmo problema, estimula-se a litigiosidade e fomenta-se a utilização de recursos processuais os mais diversos, o que finda por encarecer o custo da máquina Judiciária (mais processos, mais atos processuais, maior estrutura judiciária etc).

Em segundo lugar, a imprevisibilidade gera incerteza e esta, por sua vez, aumenta os custos de transação dos agentes econômicos, onerando toda a cadeia produtiva e, em última análise, o consumidor, com reflexos negativos para o desenvolvimento econômico, prejudicando a competição dos agentes nacionais tanto no mercado interno como internacional.

A falta de previsibilidade e estabilidade das decisões judiciais conspira contra a promoção da igualdade e favorece o surgimento ou manutenção de um ambiente marcado por privilégios, beneficiando grupos de estrato social mais elevando. Essa, aliás, é a ideia que está na origem do stares decisis no sistema de common law:

Vê-se, assim, que o stare decisis não foi instituído na common law por lei, ou por qualquer ato de autoridade. Surgiu da necessidade de coerência e de igualdade, como forma de se garantir um tratamento isonômico a todo o jurisdicionado e de legitimar as decisões tomadas pelo Poder Judiciário, que sofre de um déficit democrático. ${ }^{49}$

Um cenário onde as práticas jurídicas estão assim conformadas é sem dúvida o retrato de um sistema de justiça frágil, instável e inibidor da coesão social. Nesse sentido, adverte Luiz Guilherme Marinoni, o sistema jurídico brasileiro é privado de efetividade, pois "não tem sido capaz de permitir previsões e qualificações jurídicas unívocas"

\footnotetext{
${ }^{49}$ PUGLIESE, William. Precedentes e a Civil Law Brasileira. São Paulo: Revista dos Tribunais, 2016, p. 47.

${ }^{50}$ MARINONI, Luiz Guilherme. Precedentes Obrigatórios. $4^{\mathrm{a}}$ ed. São Paulo: Revista dos Tribunais, 2016, p. 100.
} 
Revista Eletrônica de Direito Processual - REDP.

Rio de Janeiro. Ano 12. Volume 19. Número 1. Janeiro a Abril de 2018

Periódico Quadrimestral da Pós-Graduação Stricto Sensu em Direito Processual da UERJ

Patrono: José Carlos Barbosa Moreira (in mem.). ISSN 1982-7636. pp. 62-82

www.redp.uerj.br

4.2 O mecanismo da vinculação e o fortalecimento do papel institucional do Poder Judiciário

A obrigatoriedade de observância de certos precedentes judiciais e súmulas, introduzida pelo novo Código de Processo Civil, ataca diretamente o problema da jurisprudência lotérica.

Trata-se de uma reforma institucional centrada no compromisso com a segurança jurídica no campo da aplicação do Direito, induzindo à previsibilidade e estabilidade das decisões judiciais.

A vinculação é necessária, constitucional e legal. Necessária porque vimos de uma tradição de baixa observância dos procedentes judiciais, o que significa que uma cultura de prestígio da jurisprudência, próximo ao que ocorre no sistema common law, seria de difícil alcance. Constitucional porque seguir precedentes nada mais é do que uma exigência extraível da própria Constituição, sendo um imperativo da segurança jurídica, do princípio da isonomia e do desenvolvimento ${ }^{51}$. Legal porque o texto legislativo é cogente ao dizer que os juízes e tribunais "observarão" os precedentes e enunciados de súmulas (art. 927 do Código de Processo Civil), o que significa um dever e não uma faculdade ou recomendação.

A consolidação desse mecanismo processual de atuação dos juízes e tribunais contribuirá para o fortalecimento do nosso sistema de justiça, e não o contrário. São inúmeros os benefícios institucionais, sociais e econômicos.

No plano institucional, cria-se um ambiente de fortalecimento e prestígio da interpretação jurídica, o que já é um bom começo para lidar com o problema da litigiosidade explosiva do nosso sistema, com reflexo no uso de expedientes protelatórios, favorecendo, em contrapartida, a economia processual, a duração razoável do processo e a redução dos custos de funcionamento da máquina judicial.

\footnotetext{
51 O desenvolvimento visto na perspectiva de norma jurídica constitucional de caráter fundamental: PEIXINHO, Manoel Messias; FERRARO, Suzani Andrade. Direito ao Desenvolvimento como Direito Fundamental. Disponível em: <http://www.publicadireito.com.br/conpedi/manaus/arquivos/anais/bh/manoel_messias_peixinho.pdf>. Acesso em 27 jul. 2017.
} 
Revista Eletrônica de Direito Processual - REDP.

Rio de Janeiro. Ano 12. Volume 19. Número 1. Janeiro a Abril de 2018

Periódico Quadrimestral da Pós-Graduação Stricto Sensu em Direito Processual da UERJ

Patrono: José Carlos Barbosa Moreira (in mem.). ISSN 1982-7636. pp. 62-82

www.redp.uerj.br

Sob a perspectiva social, um sistema de justiça coeso e previsível é ponto central de orientação das ações humanas e das relações sociais, prevenindo conflitos e solucionando os existentes de modo homogêneo, o que é um decisivo ingrediente para a coesão social.

Do ponto de vista econômico, a previsibilidade é um importante componente dos negócios em geral, pois reduz os custos da transação, favorece o investimento perene, permite a contratação de longo prazo, além de criar uma atmosfera propícia à produção e à transação de bens, o que é extremamente salutar para o processo de desenvolvimento.

Desse modo, dá-se o devido e responsável tratamento à posição central que o Poder Judiciário assume na estrutura de um Estado Democrático de Direito, no qual a ordem jurídica e os direitos fundamentais realmente importam.

Claudia Maria Barbosa adverte, por outro lado, que o sistema de precedentes apresenta desvantagens que fragilizam a coerência do sistema jurídico e, portanto, devem ser combatidas. No common law os precedentes são fontes do direito e são responsáveis pelo fechamento do sistema jurídico. No nosso caso, porém, a obrigatoriedade pode implicar apenas uma maior verticalização, favorecendo sempre o entendimento dos tribunais superiores, justamente os "mais sensíveis" a influências e pressões externas, seja do poder econômico, seja do poder político.

Para que o precedente possa assegurar a segurança jurídica que se busca, é preciso que expresse de fato o entendimento acerca de uma questão de direito (e nesse sentido constrói o significado da norma), situando-a e conectando-a a fatos claros e, principalmente, que seja fruto de uma deliberação e discussão real sobre as suas implicações, vinculando todas as Cortes, especialmente aquela que o protagonizou. Imperando a casuística dos precedentes, então ao invés de segurança jurídica, o sistema vai verticalizar-se ainda mais e tornar-se mais "elitista", desprezando a legítima contribuição e inovação dos juízes que estão na base.

Outro aspecto importante para a legitimidade dos precedentes obrigatórios relaciona-se à sua forma de deliberação. Não é possível que um único caso (ou poucos casos), por vezes apreciado singularmente por um único Ministro ou Desembargador relator, transforme-se em precedente, o que é um fenômeno empírico conhecido.

Por fim, Claudia Maria Barbosa assinala que os precedentes não podem ser defendidos com base na necessidade econômica, o que significaria, na prática, que a razão 
Revista Eletrônica de Direito Processual - REDP.

Rio de Janeiro. Ano 12. Volume 19. Número 1. Janeiro a Abril de 2018

Periódico Quadrimestral da Pós-Graduação Stricto Sensu em Direito Processual da UERJ

Patrono: José Carlos Barbosa Moreira (in mem.). ISSN 1982-7636. pp. 62-82

www.redp.uerj.br

econômica se sobrepõe aos direitos, o que é uma fundamentação que conflita com as bases

do Estado Social e despreza o desenvolvimento tal como defendido neste texto.

\subsection{Protagonismo do Direito e não do Poder Judiciário}

Para além do reconhecimento da importância que o Poder Judiciário tem para a construção de uma sociedade melhor, um sistema de justiça que é fiel aos seus precedentes, em última análise, densifica o próprio Direito.

O protagonismo, nessa perspectiva, não é judicial, senão do Direito.

Um sistema de justiça que preza pela previsibilidade e estabilidade é um sistema que valoriza a ordem jurídica e, por conseguinte, os direitos individuais e coletivos. Em última instância, é um sistema que confere normatividade ao princípio da segurança jurídica.

Em boa medida a resistência à obrigatoriedade dos precedentes judiciais agarra-se no discurso da independência funcional, do livre convencimento e na possibilidade de injustiça na aplicação do precedente no caso concreto ${ }^{52}$. Ocorre que o precedente judicial, se bem compreendido, é uma das facetas de exteriorização do próprio Direito, de modo que a vinculação a este não contradiz a premissa da independência funcional, pois esta não se coloca contra o Direito senão contra a interferência externa na atuação dos juízes e tribunais, corolário do princípio da separação dos poderes ${ }^{53}$.

Não há dúvida sobre o papel criativo do juiz na interpretação jurídica. A hermenêutica contemporânea tem desenvolvido suficientemente bem essa questão. A criatividade, contudo, tem grau, modos e limites que a legitimam. É nesse sentido que deve ser entendido o chamado livre convencimento, jamais como a possibilidade de dizer qualquer coisa sobre o Direito ou, o que é o mesmo, partir de um grau zero de sentido ${ }^{54}$.

\footnotetext{
${ }^{52}$ Luiz Guilherme Marinoni enfrenta e refuta uma série de argumentos contrários à força obrigatórias dos precedentes, dentre os quais a independência dos juízes (MARINONI, Luiz Guilherme. Precedentes Obrigatórios. $4^{\mathrm{a}}$ ed. São Paulo: Revista dos Tribunais, 2016, p. 139-153).

53 "Não se pode desconhecer a importância ou a necessidade da independência funcional da magistratura. Porém, essa independência não representa um fim em si mesmo; é um valor instrumental para preservar outro, qual seja, a imparcialidade do julgador... (MARINHO, Hugo Chacra Carvalho. A independência funcional dos juízes e os precedentes vinculantes. In: DIDIER JR, Fredie ... [et al.] (Coord.). Precedentes. Salvador: Juspodivm, 2015, p. 93).

${ }^{54}$ Essa também a razão pela qual o novo CPC, no art. 926, refere-se à jurisprudência íntegra e coerente. Nesse sentido: BARBOZA, Estefânia Maria de Queiroz. Stare decisis, Integridade e Segurança Jurídica: reflexões críticas a partir da aproximação dos sistemas de Common Law e Civil Law na sociedade
} 
Revista Eletrônica de Direito Processual - REDP.

Rio de Janeiro. Ano 12. Volume 19. Número 1. Janeiro a Abril de 2018

Periódico Quadrimestral da Pós-Graduação Stricto Sensu em Direito Processual da UERJ

Patrono: José Carlos Barbosa Moreira (in mem.). ISSN 1982-7636. pp. 62-82

www.redp.uerj.br

Como adverte Mauro Cappelletti, "o juiz, vinculado a precedentes ou à lei (ou a ambos),

tem como dever mínimo apoiar sua própria argumentação em tal direito judiciário ou legislativo..."55. Para além disso, o direito seria arbitrariamente criado pelo juiz do caso concreto.

Concernente ao ideal de justiça, importa reconhecer que em larga medida encontra apoio na própria segurança jurídica, sendo esta um elemento imanente à sua conformação e realização. Nesse sentido, a segurança jurídica é uma condição ineliminável para atingir a justiça, embora não suficiente para caracterizá-la ${ }^{56}$. Ademais, a ideia de justiça, na perspectiva de um sistema jurídico, não pode ser vista como uma questão de consciência individual, mas deve colher o seu sentido desde uma perspectiva compartilhada intersubjetivamente, o que conduz à prevalência dos precedentes e súmulas obrigatórios sobre as decisões casuísticas.

Em último exame, os argumentos da independência funcional, do livre convencimento e da justiça do caso concreto traduzem uma visão atomizada do sistema jurídico, como se o Direito fosse desprovido da possibilidade de consenso e do compartilhamento de uma unidade mínima de significação, o que é refutado pelos avanços da teoria hermenêutica contemporânea.

Não se pode olvidar, contudo, as objeções ao sistema de precedentes, que podem levá-lo ao protagonismo não do Direito nem do Poder Judiciário, mas de Ministros e Desembargadores, conforme acima apontado por Claudia Maria Barbosa, que ainda apresenta outro argumento crucial para a adequada compreensão do papel dos precedentes obrigatórios no direito brasileiro, qual seja, o poder "excepcional" que concedem ao Judiciário na produção do Direito. Esse poder deve estar submetido à norma, cuja aplicação não pode desvirtuar o legislador nela estabeleceu, pois isso imprimiria no precedente um déficit de legitimidade democrática.

contemporânea. Tese de Doutorado apresentada apresentada ao Programa de Pós-graduação em Direito da PUCPR. Curitiba, 2011; TRINDADE, André Karam. O controle das Decisões Judiciais e a Revolução Hermenêutica no Direito Processual Civil Brasileiro. In: STRECK, Lenio Luiz; ALVIM, Eduardo Arruda; LEITE, George Salomão. Hermenêutica e Jurisprudência no Novo Código de Processo Civil: coerência e integridade. São Paulo: Saraiva, 2016, p. 34-36.

55 CAPPELLETTI, Mauro. Juízes Legisladores? Tradução de Carlos Alberto Alvaro de Oliveira. Porto Alegre: Sérgio Antônio Fabris, 1993.

${ }_{56}$ CUNHA, Ricarlos Almagro Vitoriano. Segurança jurídica e crise no direito. Belo Horizonte: Arraes Editores, 2011, p. 51. 
Rio de Janeiro. Ano 12. Volume 19. Número 1. Janeiro a Abril de 2018 Periódico Quadrimestral da Pós-Graduação Stricto Sensu em Direito Processual da UERJ Patrono: José Carlos Barbosa Moreira (in mem.). ISSN 1982-7636. pp. 62-82 www.redp.uerj.br

\section{CONCLUSÃO}

Um país que tem compromisso com o desenvolvimento e necessita realizar as promessas da mordenidade, como o Brasil, não pode descuidar de uma condição inafastável desse processo de garantias de liberdades, qual seja o de velar por uma ordem jurídica previsível, estável e confiável. A imprevisibilidade e a desconfiança no sistema jurídico degeneram as relações sociais e impedem o florescimento das atividades econômicas, necessárias para a realização de investimentos, trocas e a circulação de riqueza.

A pesquisa mostra que as instituições são um elemento fundamental para o constrangimento de pessoas e entes e de garantia de implantação de práticas compromissadas com o objetivo do desenvolvimento. As instituições jurídicas em particular moldam o arcabouço básico que leva à confiança no sistema jurídico e à elevação do patamar de segurança jurídica desejável e esperado.

A segurança jurídica, do ponto de vista normativo, é um princípio que permeia a nossa ordem jurídica e configura o nosso Estado Democrático de Direito, portanto, que estabelece um fim a ser promovido, sob pena de violação da própria Constituição.

A vinculação das decisões judiciais aos precedentes, por isso, também é uma exigência do bom funcionamento e higidez do próprio sistema jurídico, eliminando a jurisprudência lotérica, fortalecendo o sistema de justiça e densificando o próprio Direito.

A reforma processual promovida pelo novo Código de Processo Civil no campo dos precedentes apresenta-se como um novo arranjo institucional introduzido no sistema jurídico com o propósito de conformá-lo à necessidade de previsibilidade e estabilidade, alavancas do desenvolvimento e, além disso, pressuposto de realização do próprio Direito.

Um sistema de precedentes bem estruturado e operacionalizado, que se legitima pela coerência e pela promoção da segurança jurídica, sem cair em desvios que podem conspurcar o próprio sistema jurídico, é sem dúvida bom arranjo político-jurídico para a busca do desenvolvimento e a realização dos projetos de vida que as pessoas têm razão para valorizar.

O outro lado, isto é, um sistema jurídico imprevisível e, por isso, inseguro, é um sistema jurídico caótico e que conspira contra o desenvolvimento e o Direito. 
Rio de Janeiro. Ano 12. Volume 19. Número 1. Janeiro a Abril de 2018

Periódico Quadrimestral da Pós-Graduação Stricto Sensu em Direito Processual da UERJ

Patrono: José Carlos Barbosa Moreira (in mem.). ISSN 1982-7636. pp. 62-82 www.redp.uerj.br

REFERÊNCIAS BIBLIOGRÁFICAS:

ABBOUD, Georges. Processo Constitucional Brasileiro. São Paulo: Revista dos Tribunais, 2016.

ÁVILA, Humberto. Teoria da Segurança Jurídica. $4^{\mathrm{a}}$ ed. São Paulo: Malheiros, 2016.

BARBOSA, Claudia Maria. O Processo de Legitimação do Poder Judiciário. Manaus:

CONPEDI. Disponível em:

http://www.publicadireito.com.br/conpedi/manaus/arquivos/anais/XIVCongresso/08

0.pdf>. Acesso em: 12 out. 2017.

CAPPELlETTI, Mauro. Juízes Legisladores? Tradução de Carlos Alberto Alvaro de

Oliveira. Porto Alegre: Sérgio Antônio Fabris, 1993.

CUNHA, Ricarlos Almagro Vitoriano. Segurança jurídica e crise no direito. Belo Horizonte: Arraes Editores, 2011.

DIDIER JR., Fredie; BRAGA, Paula Sarno; OLIVIERA, Rafael Alexandria de. Curso de

Direito Processual Civil: teoria da prova, direito probatório, decisão, precedente, coisa julgada e tutela provisória. Salvador: Juspodivum, 2015, v. 2.

GOUVEIA, Lúcio Grassi; BREITENBACH, Fábio Gabriel. Sistema de precedentes no novo Código de Processo Civil brasileiro: um passo para o enfraquecimento da jurisprudência lotérica dos tribunais. In: DIDIER JR, Fredie ... [et al.] (Coord.). Precedentes. Salvador: Juspodivm, 2015.

GRAU, Eros Roberto. A Ordem Econômica na Constituição de 1988. 14 $4^{\mathrm{a}}$ ed. São Paulo: Malheiros, 2010.

ISHIKAWA. O Direito ao Desenvolvimento como Concretizador do Princípio da Dignidade da Pessoa humana. Monografia de mestrado apresentada perante a PUCSP. São Paulo, 2008. Disponível em < http://www.pucsp.br/capitalismohumanista/downloads/o_direito_ao_desenvolviment o_como_concretizador_do_principio_da_dignidade_da_pessoa_humana.pdf>, acesso em 28.07.2017.

LOPES FILHO, Juraci Mourão. Os Precedentes Judiciais no Constitucionalismo Brasileiro Contemporâneo. $2^{\text {a }}$ ed. Salvador: Juspodivm, 2016.

MACÊDO, Lucas Buril. Precedentes Judiciais e o Direito Processual Civil. Salvador: Juspodivum, 2015. 
Revista Eletrônica de Direito Processual - REDP.

Rio de Janeiro. Ano 12. Volume 19. Número 1. Janeiro a Abril de 2018

Periódico Quadrimestral da Pós-Graduação Stricto Sensu em Direito Processual da UERJ

Patrono: José Carlos Barbosa Moreira (in mem.). ISSN 1982-7636. pp. 62-82

www.redp.uerj.br

MANCUSO, Rodolfo de Camargo. Sistema Brasileiro de Precedentes. $2^{\text {a }}$ ed. São Paulo:

Revista dos Tribunais, 2016.

MARINHO, Hugo Chacra Carvalho. A independência funcional dos juízes e os precedentes vinculantes. In: DIDIER JR, Fredie ... [et al.] (Coord.). Precedentes. Salvador: Juspodivm, 2015.

MARINONI, Luiz Guilherme. Precedentes Obrigatórios. $4^{\mathrm{a}}$ ed. São Paulo: Revista dos Tribunais, 2016.

MELlO, Patrícia Perrone Campos; BARROSO, Luís Roberto. Trabalhando com uma nova lógica: a ascensão dos precedentes no direito brasileiro. Revista Eletrônica Consultor Jurídico, 2016. Disponível em: < http://s.conjur.com.br/dl/artigotrabalhando-logica-ascensao.pdf>. Acesso em: 29 jul. 2017.

MOREIRA, Vital. A ordem jurídica do capitalismo. 3. ed., Coimbra: Centelho, 1978.

NASSER, Salem Hikmat. Rule of Law e Direito Internacional: uma nova aproximação. In:

VIEIRA, Oscar Vilhena; DIMOULIS, Dimitri (Org.). Estado de Direito e o Desafio do Desenvolvimento. São Paulo: Sariva, 2011.

NORTH, Douglass Cecil. Institutions, institutional change and economic performance. New York: Cambridge, 1990.

NUSDEO, Fábio. Curso de Economia: introdução ao Direito Econômico. $8^{\mathrm{a}}$ ed. São Paulo:Revista dos Tribunais, 2014.

PEIXINHO, Manoel Messias; FERRARO, Suzani Andrade. Direito ao Desenvolvimento como Direito $\quad$ Fundamental. $\quad$ Disponível em <http://www.publicadireito.com.br/conpedi/manaus/arquivos/anais/bh/manoel_messi as_peixinho.pdf>. Acesso em: 27.07.2017.

PUGLIESE, William. Precedentes e a Civil Law Brasileira. São Paulo: Revista dos Tribunais, 2016.

RIBEIRO, Marcia Carla Pereira; ALVES, G. R. R. Desenvolvimento e Reforma Institucional: os exemplos do BNDES e das Sociedades Estatais no Brasil. In: SILVEIRA, Vladimir Oliveira da; SANCHES, Samyra Naspolini; COUTO, Monica Bonetti (Org.). Direito e Desenvolvimento no Brasil do Século XXI. IPEA: Brasília, v.1, 2013.

ROCHA, Lara Bonemer Azevedo da. O desenvolvimento Econômico pelo Acesso à Justiça. Birigui, SP: Boreal Editora, 2015. 
Revista Eletrônica de Direito Processual - REDP.

Rio de Janeiro. Ano 12. Volume 19. Número 1. Janeiro a Abril de 2018

Periódico Quadrimestral da Pós-Graduação Stricto Sensu em Direito Processual da UERJ

Patrono: José Carlos Barbosa Moreira (in mem.). ISSN 1982-7636. pp. 62-82 www.redp.uerj.br

ROCHA, Lara Bonemer Azevedo da; BARBOSA, Claudia Maria. O papel dos precedentes para o controle do ativismo judicial no contexto pós-positivista. Revista Brasileira de Políticas Públicas, v. 5, 2015.

SALAM, Bruno Meyerhof. Sete enigmas do desenvolvimento em Douglass North. In: VIEIRA, Oscar Vilhena; DIMOULIS, Dimitri (Org.). Estado de Direito e o Desafio do Desenvolvimento. São Paulo: Sariva, 2011.

SEN, Amartya. Desenvolvimento como liberdade. Tradução de Laura Teixeira Motta. São Paulo: Companhia das Letras, 2010.

STRECK, Lenio Luiz. Dicionário de Hermenêutica. Belo Horizonte: Letramento: Casa do Direito, 2017.

O que é isto - decido conforme a minha consciência? 3a ed. Porto Alegre: Livraria do Advogado, 2012.

Verdade e Consenso. $4^{\text {a }}$ ed. São Paulo: Saraiva, 2011.

TRINDADE, André Karam. O controle das Decisões Judiciais e a Revolução Hermenêutica no Direito Processual Civil Brasileiro. In: STRECK, Lenio Luiz; ALVIM, Eduardo Arruda; LEITE, George Salomão. Hermenêutica e Jurisprudência no Novo Código de Processo Civil: coerência e integridade. São Paulo: Saraiva, 2016. 